Dhaka Univ. J. Sci. 60(1): 129-136, 2012 (January)

\title{
Effect of Sodium Dodecyl Sulfate on Volumetric Properties of Methanol Ethanol n- Propanol and iso-Propanol at (298.15 - 323.15)K
}

\author{
M. A. Motin ${ }^{1 *}$, M. A. Hafiz Mia ${ }^{1}$, K. M. Salim Reza, ${ }^{1}$ A. K. M Nasimul Islam, ${ }^{1}$ M. A. Yousuf ${ }^{1}$ and M. A. Salam ${ }^{2}$ \\ ${ }^{1}$ Department of Chemistry, Khulna University of Engineering \& Technology (KUET), Khulna 9203, Bangladesh \\ ${ }^{2}$ Department of Chemistry, University of Dhaka, Dhaka-1000, Bangladesh
}

Received on 12.09.2011. Accepted for Publication on 24. 11. 2011

\begin{abstract}
The critical micelle concentration (CMC) of Sodium dodecyl sulfate (SDS) in water was determined from the conductance and viscosity measurement. The estimated value of CMC was found to be $0.0085 \mathrm{~mol} . \mathrm{L}^{-1}$ at $29^{\circ} \mathrm{C}$. The concentration of SDS in pre-micellar and postmicellar region of $0.005 \mathrm{M}$ and $0.01 \mathrm{M}$, respectively were used for the volumetric measurements of Methanol, Ethanol, $n$-Propanol and isoPropanol with SDS solutions. Densities of ternary mixtures of Methanol, Ethanol, $n$-Propanol and iso-Propanol with $0.005 \mathrm{M}$ and $0.01 \mathrm{M}$ aqueous SDS have been studied over the entire range of composition at 298.15-323.15K with an interval of 5K except Methanol. Methanol system was studied at $298.15-308.15 \mathrm{~K}$ due to its low boiling point. The values of excess molar volumes, $V^{E}$ for all the systems are negative over the entire range of composition, showing minima at $\sim 0.45$ mole fraction of Methanol, $\sim 0.4$ mole fraction of Ethanol, 0.25 mole fraction of $n$-Propanol and $\sim 0.3$ mole fraction of $i$ so-Propanol. All the systems are showing minima at aqueous SDS rich region. The $V^{E}$ values for the $n$-Propanol + aqueous SDS and iso-Propanol + aqueous SDS mixtures are slightly sigmoid, being negative at lower mole fractions $\left(\mathrm{x}_{2}\right)$ and positive at higher $\mathrm{x}_{2}$ of Propanols. The excess properties $\left(V^{E}\right)$ data have been fitted by the least square method to the four parameter Redlich-Kister equation and the values of the parameter $a_{j}$ have been reported.
\end{abstract}

Keywords: Excess molar volume, SDS, Alcohols

\section{Introduction}

Solution of highly surface-active materials exhibit unusual physical properties. In dilute solution the surfactant acts as a normal solute. By increasing the concentration of the surfactant, an abrupt change in several physico-chemical properties of the solution, such as osmotic pressure, electrical conductance, surface tension, viscosity etc. is observed Micelle formation of surfactant molecules in water solution is a typical hydrophobic process [1]. In water medium, surfactant molecules with their long hydrophobic tails undergo hydrophobic hydration.

Alcohols are self-associated liquids through H-bonding. Alcohols possess hydrophilic -OH group as well as hydrophobic group. Interactions between aqueous SDS and alcohols are extremely complex. The mode of interaction of these two groups towards SDS is completely different. The hydrophilic - $\mathrm{OH}$ group of an alcohol forms H-bond with aqueous SDS through hydrophilic interactions and disrupts the aqueous SDS structure, while the alkyl group promotes the structure of aqueous SDS molecules surrounding this group, through hydrophobic hydration. Recently, we reported the densities and excess molar volumes of alcohols in water Surf Excel solution [2] and the volumetric and viscometric properties of carbohydrates in water Surf Excel [3] and the electrolytes in water SDS [4] systems. Research on some binary alcohol systems thermophysical properties has been reported by several authors [5-12].
Here, we report the effect of some simple alcohols on the structure of water SDS systems based on volumetric measurements. Micelle-forming molecules in SDS may force water to be in a certain structural form in the water SDS system. The perturbations of this forced structure in water SDS system by some alcohols are expected to be more appreciable than the perturbation caused by these alcohols in only the water system. The knowledge of interactions of simple smaller hydrophobic molecules with water and with water surfactant solvent systems may be useful sometimes to interpret many complex systems. The data are also useful for the design of mixing, storage and process equipment.

\section{Experimental}

Materials. The chemicals used were purchased from Aldrich chemical co. with the quoted purities : Methanol (99.5\%), Ethanol (99.0\%), n-Propanol (99.0\%), and iso-Propanol $(99.5 \%)$ sodium dodecyl sulfate (SDS) (99.5\%).These alcohols were used without any further purification, except that they were allowed to stand over molecular sieves (4A) about one week before measurements.

Density Measurements. Densities were measured by using 5 $\mathrm{mL}$ bicapillary pycnometers. The volumes of the pycnometers were calibrated with deionized and doubly distilled water at $(298.15,303.15,308.15,313.15,318.15$ and 323.15) K. The densities of solutions were determined from the mass of the solution in the pycnometer after reaching thermal equilibrium with a water bath at the

*Corresponding author: abdulmotin75@yahoo.com (M. A. Motin), Fax : +88 041774403 
studied temperatures. Temperatures were controlled by a thermostatic water bath fluctuating to $\pm 0.05 \mathrm{~K}$. A HR-200 electronic balance with an accuracy of $\pm 0.0001 \mathrm{~g}$ was used for the mass determination. Reproducibility of the results was checked by taking each measurement three times. The density, $\rho$ was reproducible to within $\pm 2 \times 10^{-5}{\mathrm{~g} . \mathrm{cm}^{-3}}$.

\section{Results and Discussion}

The critical micelle concentration (CMC) of surfactant in aqueous solution is one of the most important properties in the formation of micelle. This property has significant importance for quantitative study of the thermodynamics of interactions involved in the monomer micelle equilibrium as well as in systems involving solubilization of an additional component or its distribution between bulk solution and micelle.

The CMC of sodium dodecyl sulfate (SDS) in water was determined from the conductance and viscosity measurement. The concentration dependence of molar conductivity of aqueous solutions of SDS is shown in Figure 1(a). The molar conductivity decreases with increasing SDS concentration and then remains unchanged and finally decreases again. It shows a sharp break in its value where micelle starts to form and it is determined by extrapolating the molar conductivity data in the pre-micellar region to intersect with a straight line drawn through the data in the post-micellar region.

Viscosities vs. concentration of aqueous solution of SDS are plotted in Figure 1(b). The viscosities increases with increasing SDS concentration and then decreases and eventually increases again. The minima of viscosity express the CMC of SDS. The estimated value of CMC was found to be $0.0085 \mathrm{~mol} . \mathrm{L}^{-1}$ at $29^{\circ} \mathrm{C}$. The conductance data is in good agreement with the viscosity data. The literature value also has been found to be satisfactory with this data [13]. The effect of surfactant, SDS to alcohol systems has been studied in terms of volumetric, viscometric and thermodynamic properties. The concentration of SDS in premicellar and post-micellar region of $0.005 \mathrm{M}$ and $0.01 \mathrm{M}$ respectively were used for these measurements. The densities, $\rho$ of Methanol, Ethanol, $n$-Propanol and isoPropanol in $0.005 \mathrm{M}$ and $0.01 \mathrm{M}$ SDS systems were determined at temperatures ranging from (298.15, 303.15, $308.15,313.15,318.15$ and 323.15$) \mathrm{K}$ except methanol with an interval of $5 \mathrm{~K}$ over the entire composition range $0<\mathrm{x}_{2}<$ 1 , where $\mathrm{x}_{2}$ represents the mole fraction of Alkanols. Methanol system was studied at 298.15, 303.15 and $308.15 \mathrm{~K}$ for its lower boiling point. The densities and viscosities of the pure components are shown in Table 1 together with the literature values, for possible comparison. The agreement between the measured values and literature values has been found to be quite satisfactory.

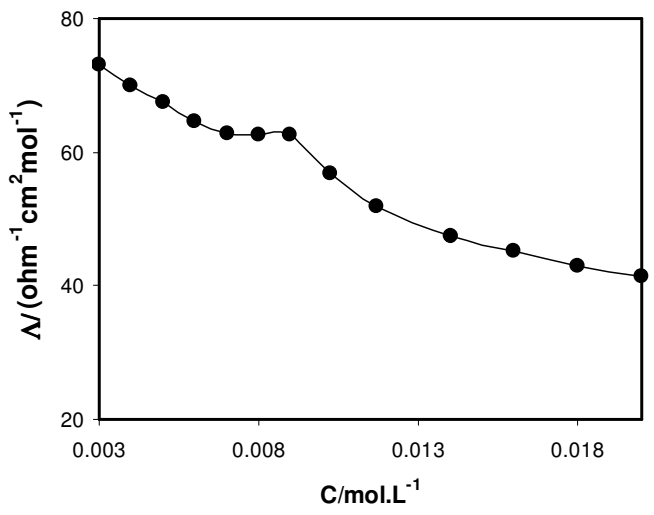

(a)

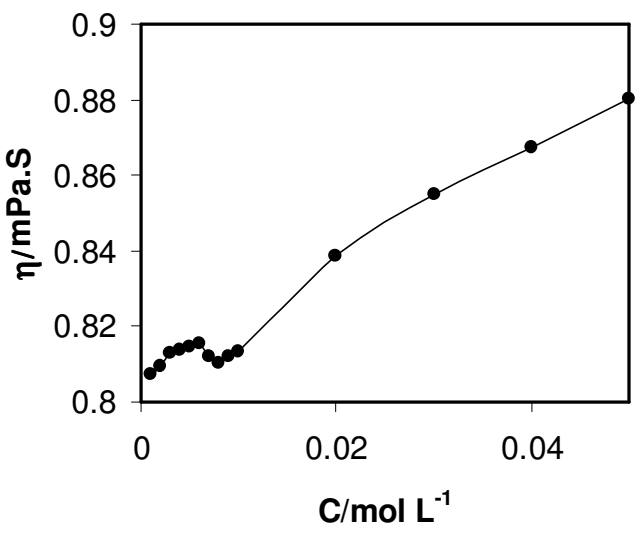

(b)

Fig. 1. Plots of Molar conductance (a) and viscosity (b) vs. concentration of SDS in aqueous solution at $302.15 \mathrm{~K}$.

The concentration of SDS in pre-micellar and post-micellar region of $0.005 \mathrm{M}$ and $0.01 \mathrm{M}$, respectively were used for the density measurement. Figure 2 shows the plots of densities as a function of mole fraction of Ethanol in 0.01M SDS solutions as sample.

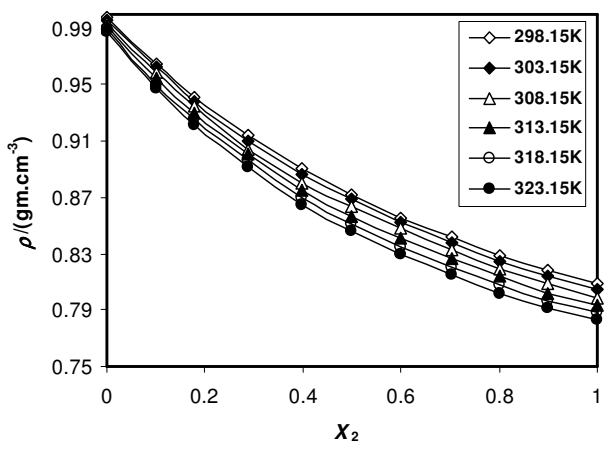

Fig. 2. Plots of density vs mole fraction of Ethanol + 0.01M SDS system at $298.15 \mathrm{~K}, 303.15 \mathrm{~K}, 308.15 \mathrm{~K}, 313.15 \mathrm{~K}, 318.15 \mathrm{~K}$, $323.15 \mathrm{~K}$ respectively 


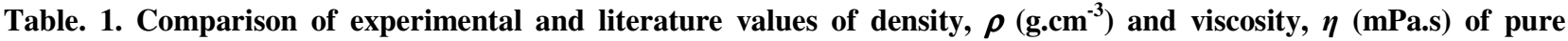
components at different temperatures.

\begin{tabular}{|c|c|c|c|c|c|}
\hline \multirow[t]{2}{*}{ Component } & \multirow[t]{2}{*}{ Temperature (K) } & \multicolumn{2}{|c|}{ Density $\left(\mathrm{g} . \mathrm{cm}^{-3}\right)$} & \multicolumn{2}{|c|}{ Viscosity (mPa.s) } \\
\hline & & $\rho_{\text {lit }}$ & $\rho_{\exp }$ & $\eta_{\text {lit }}$ & $\eta_{\exp }$ \\
\hline \multirow[t]{6}{*}{ Methanol } & 298.15 & $0.787200(14)$ & 0.787323 & $0.5530(23)$ & 0.5523 \\
\hline & 303.15 & $0.782420(15)$ & 0.782764 & $0.5100(24)$ & 0.5108 \\
\hline & 308.15 & $0.777100(16)$ & 0.777426 & $0.4837(25)$ & 0.4902 \\
\hline & 313.15 & $0.772500(17)$ & 0.772540 & $0.4542(25)$ & 0.4577 \\
\hline & 318.15 & $0.769285(18)$ & 0.766700 & $0.4256(25)$ & 0.4280 \\
\hline & 323.15 & $0.762800(17)$ & 0.758600 & $0.4000(23)$ & 0.4055 \\
\hline \multirow[t]{6}{*}{ Ethanol } & 298.15 & $0.801900(19)$ & 0.808867 & $1.0900(23)$ & 1.1355 \\
\hline & 303.15 & $0.798255(18)$ & 0.804509 & $1.1808(25)$ & 1.2060 \\
\hline & 308.15 & $0.794517(18)$ & 0.799029 & $1.0638(25)$ & 1.0871 \\
\hline & 313.15 & $0.780157(18)$ & 0.793200 & $0.9646(25)$ & 0.9655 \\
\hline & 318.15 & $0.785760(18)$ & 0.788300 & $0.8714(25)$ & 0.8708 \\
\hline & 323.15 & $0.771336(18)$ & 0.783558 & $0.8010(25)$ & 0.7952 \\
\hline \multirow[t]{6}{*}{ n-Propanol } & 298.15 & $0.799692(20)$ & 0.800501 & $1.9340(26)$ & 1.9233 \\
\hline & 303.15 & $0.795840(15)$ & 0.796323 & $1.6626(15)$ & 1.6951 \\
\hline & 308.15 & $0.797499(18)$ & 0.791910 & $1.5422(25)$ & 1.5234 \\
\hline & 313.15 & $0.787500(17)$ & 0.787892 & $1.3000(23)$ & 1.3430 \\
\hline & 318.15 & $0.789183(18)$ & 0.782407 & $1.2440(25)$ & 1.2060 \\
\hline & 323.15 & $0.778500(17)$ & 0.779224 & $1.1091(25)$ & 1.0690 \\
\hline \multirow[t]{6}{*}{ iso-Propanol } & 298.15 & $0.780000(21)$ & 0.778306 & $2.0360(27)$ & 2.0257 \\
\hline & 303.15 & $0.777100(19)$ & 0.774467 & - & 1.7639 \\
\hline & 308.15 & $0.772460(22)$ & 0.771190 & $1.5420(22)$ & 1.5220 \\
\hline & 313.15 & - & 0.766972 & - & 1.3179 \\
\hline & 318.15 & - & 0.762585 & - & 1.1516 \\
\hline & 323.15 & - & 0.758129 & - & 1.0075 \\
\hline
\end{tabular}

The densities, $\rho$ of Ethanol and $n$-Propanol in 0.01M SDS systems are presented in the Table 2-3 (for similar nature data of $0.005 \mathrm{M}$ SDS containing all studied alcohol systems and Methanol and iso-Propanol in 0.01M SDS systems are not shown). It shows continuous decrease in density on addition of Methanol, Ethanol, $n$-Propanol and iso-Propanol systems. In Ethanol, $n$-Propanol and iso-Propanol systems the decrease in density is found firstly rapid and beyond the 0.4 mole fraction it shows slowlness on addition of solute. The concave density curves for Ethanol, $n$-Propanol and isoPropanol systems show that at lower mole fraction of solute, the rate of change of density with temperature appears to be much higher than the rate at higher mole fraction of solute. Density value decreases with increase in the temperature. As the densities of pure Methanol, Ethanol, $n$-Propanol and iso-Propanol are less than that of pure water, with the increase of concentration of alcohol the density of alcohol + water system decreases and eventually proceeds towards the density of pure alcohol.

The excess molar volume, $V^{\mathrm{E}}$ of Methanol, Ethanol, $n$ Propanol and iso-Propanol in aqueous SDS systems have been calculated from density data of these systems using equation (1),

$$
V^{E}=\frac{X_{1} M_{1}+X_{2} M_{2}}{\rho_{\text {mix }}}-\left(\frac{X_{1} M_{1}}{\rho_{1}}+\frac{X_{2} M_{2}}{\rho_{2}}\right) \ldots \ldots \ldots \ldots
$$

Where $X_{1}, M_{1}$, and $\rho_{1}$ are the mole fraction, molar mass and density of component 1 (solvent); $X_{2}, M_{2}$, and $\rho_{2}$ are the corresponding values of component 2(organic solutes); and $\rho_{\text {mix }}$ is the density of the mixture, respectively.

The values of $V^{E}$ at different temperatures have been shown in Table 2-3. The excess molar volumes were fitted to a Redlich-Kister polynomial equation of the form,

$$
V^{E}=X_{1} X_{2} \sum_{i=0}^{n} \mathrm{a}_{\mathrm{i}}\left(1-2 X_{1}\right)^{\mathrm{i}} \quad \ldots \ldots \ldots \ldots \ldots
$$

Where $a_{i}$ is the ith fitting coefficient. Using $n=3$ four $a_{i}$ coefficient and the standard deviation $\sigma$ were obtained through the least square method. For $V^{\mathrm{E}}$ the fitting coefficients $\left(\mathrm{a}_{\mathrm{i}}\right)$ of Ethanol systems are shown in Table 4 along with standard deviations as sample. Figure 3 and 4 show the plots of excess molar volume as a function of mole fraction of Methanol and iso-Propanol in 0.01M SDS, respectively at different temperatures as sample.

The values have been found to be negative throughout the whole range of composition, showing minima at $\sim 0.45$ mole fraction of Methanol. The temperature variation of 
excess molar volume is not appreciable. For Ethanol, the values of $V^{\mathrm{E}}$ are negative throughout the whole range of composition. The minima appear at $\sim 0.4$ mole fraction of Ethanol.

At low concentration of $n$-Propanol, $V^{\mathrm{E}}$ are negative and with the increase of alcohol concentration, $V^{\mathrm{E}}$ reaches minimum value between 0.2-0.3 mole fraction of $n$ Propanol and then increases continuously and eventually becomes positive. At lower concentration of iso-Propanol, $V^{\mathrm{E}}$ are negative and with the increase of alcohol concentration, $V^{\mathrm{E}}$ reaches minimum value at $\sim 0.3$ mole fraction of iso-Propanol and then increases continuously and finally becomes positive at higher temperature. In the present investigation at $298.15 \mathrm{~K}$, the minimum values $V^{\mathrm{E}}$ have been found to be -1.1721 (at $\mathrm{x}_{2}=0.30$ ), -1.0911 (at $\mathrm{x}_{2}=$ $0.5),-0.8340\left(\right.$ at $\left.\mathrm{x}_{2}=0.389\right),-0.5880\left(\right.$ at $\mathrm{x}_{2}=0.3$ ) for the SDS + iso-Propanol, SDS + Methanol, SDS + Ethanol and $\mathrm{SDS}+n$-Propanol mixtures, respectively.

Examination of the excess molar volume curves in the Figures reveals the following characteristics:

a) The mixing of alcohols with aqueous SDS is accompanied by significant contractions of volume i.e $V^{E}$ are negative and large in magnitude.

b) All systems show well defined minima.

c) Temperature effects on $V^{\mathrm{E}}$ are not much significant.

d) $n$-Propanol and iso-Propanol, the $V^{\mathrm{E}}$ are being slightly positive at higher mole fractions and higher temperature.

In general, the sign of $V^{\mathrm{E}}$ depends upon the relative magnitude of contractive and expansive effects that arise on mixing of the components. The factors that cause contraction on mixing are:

a) Strong specific interactions, usually a kind of chemical interaction,

b) Strong physical interactions, such as dipole-dipole or dipole-induced dipole interactions or Vander Waals forces that operate between component molecules,

c) Interstitial accommodation of molecules of one component into the structural network of molecules of the other component. This is expected when the molecular sizes of the compounds differ by a large magnitude,

d) Favorable geometrical fitting of component molecules,

e) The aqueous SDS structure around the hydrocarbon moieties of aliphatic alcohol is highly promoted leading to the formation of cages surrounding the alcohol molecules. This is a special type of interactions, which occurs in aqueous SDS rich region when an organic solute molecule is surrounded by a network of highly ordered water molecules.

The factors that cause expansion of volume on mixing of the components are:

a) The dispersive forces which occur predominantly in systems consisting of associated species (formed either by chemical or physical forces) and non-polar components,

b) Dissociation of one component or both of the components,

c) Steric hindrance,

d) Geometrical mismatch of the molecules,

e) Formation of weaker solute- solvent bond than solute - solute and solvent - solvent bonds,

f) Effect due to differences in the chain length of alkanols,

g) Electrostatic repulsive forces.

Therefore, the observed $V^{\mathrm{E}}$ may be discussed above which may be arbitrarily divided into physical, chemical, and geometrical contributions. The chemical or specific intermolecular interactions result in a volume decrease and these interactions include formation of hydrogen bonds and other complex-forming interactions. The structural contributions for these systems are mostly negative and arise from several effects, especially from interstitial accommodation and changes of free volume.

In other words, structural contributions arising from geometrical fitting (interstitially accommodated) of one component into another due to the differences in the free volume and molar volume between components lead to a negative contribution to $V^{\mathrm{E}}$. The physical interactions, that is, nonspecific interactions between the real species present in the mixture, involve mainly dispersion force giving a positive contribution.

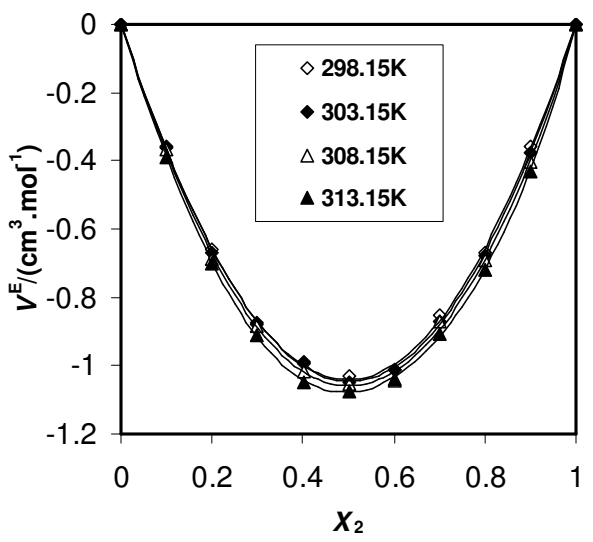

Fig. 3. Plots of excess molar volume vs mole fraction of Methanol $+0.01 \mathrm{M}$ SDS system at $298.15 \mathrm{~K}, 303.15 \mathrm{~K}, 308.15 \mathrm{~K}$, and $313.15 \mathrm{~K}$ respectively. 
Table. 2. Density $(\rho)$, and Excess molar volume $\left(V^{\mathrm{E}}\right)$ of Ethanol $+0.01 \mathrm{M}$ SDS system at 298.15K, 303.15K, 308.15K, 313.15K, 318.15K, 323.15K respectively.

\begin{tabular}{|c|c|c|c|c|c|c|c|c|c|c|c|c|}
\hline \multirow[t]{3}{*}{$X_{2}$} & \multicolumn{2}{|c|}{$298.15 \mathrm{~K}$} & \multicolumn{2}{|c|}{$303.15 \mathrm{~K}$} & \multicolumn{2}{|c|}{$308.15 \mathrm{~K}$} & \multicolumn{2}{|c|}{$313.15 \mathrm{~K}$} & \multicolumn{2}{|c|}{$318.15 \mathrm{~K}$} & \multicolumn{2}{|c|}{$323.15 \mathrm{~K}$} \\
\hline & $\rho$ & $V^{E}$ & $\rho$ & $V^{E}$ & $\rho$ & $V^{E}$ & $\rho$ & $V^{E}$ & $\rho$ & $V^{E}$ & $\rho$ & $V^{E}$ \\
\hline & $\mathrm{gcm}^{-3}$ & $\begin{array}{c}\mathrm{cm}^{3} \\
\mathrm{~mol}^{-1}\end{array}$ & $\mathrm{gcm}^{-3}$ & $\begin{array}{c}\mathrm{cm}^{3} \\
\mathrm{~mol}^{-1}\end{array}$ & $\mathrm{gcm}^{-3}$ & $\begin{array}{c}\mathrm{cm}^{3} \\
\mathrm{~mol}^{-1}\end{array}$ & $\mathrm{gcm}^{-3}$ & $\mathrm{~cm}^{3} \mathrm{~mol}_{\mathrm{l}}^{-}$ & $\mathrm{gcm}^{-3}$ & $\begin{array}{c}\mathrm{cm}^{3} \\
\mathrm{~mol}^{-1}\end{array}$ & $\mathrm{gcm}^{-3}$ & $\begin{array}{c}\mathrm{cm}^{3} \\
\mathrm{~mol}^{-1}\end{array}$ \\
\hline 0.000 & 1.001509 & 0.0000 & 0.999900 & 0.0000 & 0.997549 & 0.0000 & 0.995318 & 0.0000 & 0.993491 & 0.0000 & 0.991432 & 0.0000 \\
\hline 0.1005 & 0.967509 & -0.3700 & 0.966216 & -0.3982 & 0.963606 & -0.4175 & 0.959740 & -0.4035 & 0.953859 & -0.3410 & 0.948400 & -0.2854 \\
\hline 0.1997 & 0.941630 & -0.6882 & 0.938056 & -0.6775 & 0.933945 & -0.6790 & 0.928700 & -0.6415 & 0.922850 & -0.5893 & 0.915870 & -0.4965 \\
\hline 0.2992 & 0.913911 & -0.7504 & 0.911437 & -0.7846 & 0.907060 & -0.7921 & 0.902300 & -0.7761 & 0.896800 & -0.7432 & 0.890800 & -0.6793 \\
\hline 0.3989 & 0.891935 & -0.7876 & 0.889039 & -0.8215 & 0.883397 & -0.7938 & 0.878500 & -0.7795 & 0.872248 & -0.7256 & 0.866616 & -0.6747 \\
\hline 0.4988 & 0.874371 & -0.8174 & 0.869930 & -0.7989 & 0.863900 & -0.7593 & 0.859100 & -0.7547 & 0.853600 & -0.7369 & 0.847600 & -0.6704 \\
\hline 0.6005 & 0.856899 & -0.7044 & 0.851106 & -0.6243 & 0.845600 & -0.6104 & 0.840800 & -0.6105 & 0.834638 & -0.5652 & 0.830196 & -0.5736 \\
\hline 0.7019 & 0.843129 & -0.6172 & 0.838754 & -0.6092 & 0.832600 & -0.5652 & 0.826800 & -0.5159 & 0.821600 & -0.5265 & 0.816400 & -0.4988 \\
\hline 0.8017 & 0.830048 & -0.4283 & 0.825634 & -0.4206 & 0.819470 & -0.3748 & 0.814000 & -0.3434 & 0.808000 & -0.3109 & 0.802871 & -0.2876 \\
\hline 0.9002 & 0.819610 & -0.2736 & 0.815125 & -0.2638 & 0.810395 & -0.3117 & 0.804400 & -0.2466 & 0.798000 & -0.1895 & 0.793200 & -0.1901 \\
\hline 1.0000 & 0.808867 & 0.0000 & 0.804509 & 0.0000 & 0.799029 & 0.0000 & 0.794000 & 0.0000 & 0.788400 & 0.0000 & 0.783558 & 0.0000 \\
\hline
\end{tabular}

Table. 3. Density $(\rho)$, and Excess molar volume $\left(V^{E}\right)$ of n-Propanol + 0.01M SDS system at 298.15K, 303.15K, 308.15K, 313.15K, 318.15K, 323.15K respectively.

\begin{tabular}{|c|c|c|c|c|c|c|c|c|c|c|c|c|}
\hline \multirow[t]{3}{*}{$X_{2}$} & \multicolumn{2}{|c|}{$298.15 \mathrm{~K}$} & \multicolumn{2}{|c|}{$303.15 \mathrm{~K}$} & \multicolumn{2}{|c|}{$308.15 \mathrm{~K}$} & \multicolumn{2}{|c|}{$313.15 \mathrm{~K}$} & \multicolumn{2}{|c|}{$318.15 \mathrm{~K}$} & \multicolumn{2}{|c|}{$323.15 \mathrm{~K}$} \\
\hline & $\rho$ & $V^{E}$ & $\rho$ & $V^{E}$ & $\rho$ & $V^{E}$ & $\rho$ & $V^{E}$ & $\rho$ & $V^{E}$ & $\rho$ & $V^{E}$ \\
\hline & $\mathrm{gcm}^{-3}$ & $\begin{array}{c}\mathrm{cm}^{3} \\
\mathrm{~mol}^{-1}\end{array}$ & $\mathrm{gcm}^{-3}$ & $\begin{array}{c}\mathrm{cm}^{3} \\
\mathrm{~mol}^{-1}\end{array}$ & $\mathrm{gcm}^{-3}$ & $\begin{array}{c}\mathrm{cm}^{3} \\
\mathrm{~mol}^{-1}\end{array}$ & $\mathrm{gcm}^{-3}$ & $\begin{array}{c}\mathrm{cm}^{3} \\
\mathrm{~mol}^{-1}\end{array}$ & $\mathrm{gcm}^{-3}$ & $\begin{array}{c}\mathrm{cm}^{3} \\
\mathrm{~mol}^{-1}\end{array}$ & $\mathrm{gcm}^{-3}$ & $\begin{array}{c}\mathrm{cm}^{3} \\
\mathrm{~mol}^{-1}\end{array}$ \\
\hline 0.0000 & 1.001509 & 0.0000 & 0.999900 & 0.0000 & 0.997549 & 0.0000 & 0.995318 & 0.0000 & 0.993491 & 0.0000 & 0.991432 & 0.0000 \\
\hline 0.1006 & 0.955353 & -0.4426 & 0.951882 & -0.4233 & 0.948164 & -0.4122 & 0.945105 & -0.4301 & 0.940744 & -0.3862 & 0.939865 & -0.4295 \\
\hline 0.2005 & 0.917694 & -0.6089 & 0.913223 & -0.5699 & 0.907800 & -0.5151 & 0.904700 & -0.5620 & 0.901576 & -0.5577 & 0.897520 & -0.5181 \\
\hline 0.2991 & 0.888902 & -0.6360 & 0.884306 & -0.5952 & 0.877377 & -0.4775 & 0.871500 & -0.4413 & 0.867392 & -0.4034 & 0.863875 & -0.3800 \\
\hline 0.3990 & 0.868135 & -0.6729 & 0.862923 & -0.6053 & 0.854900 & -0.4201 & 0.850000 & -0.4374 & 0.844600 & -0.3357 & 0.840400 & -0.2776 \\
\hline 0.5026 & 0.850533 & -0.6315 & 0.844575 & -0.5190 & 0.837193 & -0.3426 & 0.832033 & -0.3594 & 0.829763 & -0.4236 & 0.824281 & -0.2862 \\
\hline 0.6011 & 0.837747 & -0.6038 & 0.833266 & -0.5741 & 0.824900 & -0.3167 & 0.820000 & -0.3621 & 0.815500 & -0.2949 & 0.811900 & -0.2631 \\
\hline 0.7022 & 0.826175 & -0.5015 & 0.821580 & -0.4647 & 0.813242 & -0.1790 & 0.808938 & -0.2806 & 0.803423 & -0.1334 & 0.801108 & -0.1939 \\
\hline 0.7993 & 0.817406 & -0.4279 & 0.813000 & -0.4062 & 0.805200 & -0.1354 & 0.799000 & -0.1018 & 0.796400 & -0.1781 & 0.791700 & -0.0514 \\
\hline 0.8998 & 0.808564 & -0.2435 & 0.803100 & -0.1307 & 0.797404 & -0.0163 & 0.791700 & -0.0289 & 0.787600 & 0.0193 & 0.784232 & 0.0378 \\
\hline 1.0000 & 0.800501 & 0.0000 & 0.796323 & 0.0000 & 0.791910 & 0.0000 & 0.786000 & 0.0000 & 0.782407 & 0.0000 & 0.779224 & 0.0000 \\
\hline
\end{tabular}


Table. 4. Coefficient, $a_{i}$, of Redlich-Kister Equation expressing $V^{E}$ and standard deviation, $\sigma$ for the Ethanol, $+0.005 M$ SDS, + 0.01M SDS systems.

\begin{tabular}{ccccccc}
\hline Systems & $T / \mathrm{K}$ & $a_{o}$ & $a_{1}$ & $a_{2}$ & $a_{3}$ & $\sigma$ \\
\hline $\begin{array}{c}\text { 0.005M SDS + } \\
\text { Ethanol, }\end{array}$ & 298.15 & -3.0357 & 0.7352 & -0.1443 & 0.9784 & 0.0200 \\
systems & 303.15 & -3.0677 & 0.5515 & -0.3746 & 1.3065 & 0.0178 \\
& 308.15 & -3.0850 & 0.0578 & -0.0886 & 2.2756 & 0.0214 \\
& 313.15 & -2.8403 & 0.4732 & -0.3030 & 1.3522 & 0.0296 \\
& 318.15 & -2.8209 & 1.0863 & 0.1800 & 0.6220 & 0.0309 \\
& 323.15 & -2.6724 & 1.0845 & 0.4608 & 1.3406 & 0.0287 \\
0.01M SDS & 298.15 & -3.1525 & 1.0167 & -0.7691 & -0.1146 & 0.0314 \\
+Ethanol & 303.15 & -3.0838 & 1.5090 & -1.0031 & -0.8704 & 0.0322 \\
systems & 308.15 & -2.9376 & 1.8283 & -1.4218 & -1.4424 & 0.0316 \\
& 313.15 & -2.9193 & 1.7820 & -0.7887 & -0.9735 & 0.0211 \\
& 318.15 & -2.8321 & 1.5448 & -0.1977 & -0.6617 & 0.0342 \\
& 323.15 & -2.6784 & 1.2126 & 0.1854 & -0.7117 & 0.0280 \\
\hline
\end{tabular}

The large negative $V^{\mathrm{E}}$ of the systems, a typical characteristic of hydrophobic solutes, lead to the conviction that the factors causing the volume contraction far outweigh the factor which is to responsible for volume expansion [28]. Of the contractive factors, perhaps the hydrophobic hydration is by far the most effective one in volume reduction, as through this process the hydrophobic molecules occupy the spaces inside the so-called cages formed by the highly structured aqueous molecules, and thus ensure maximum economy of volume. Whereas in other cases, shrinkage takes place through strong interactions or attractive forces whose contribution to volume reduction is only relatively small. The minima of $V^{\mathrm{E}}$ of the systems are also may be due to the micelle formation of SDS. However, further studies are necessary for the confirmation of micelle formation.

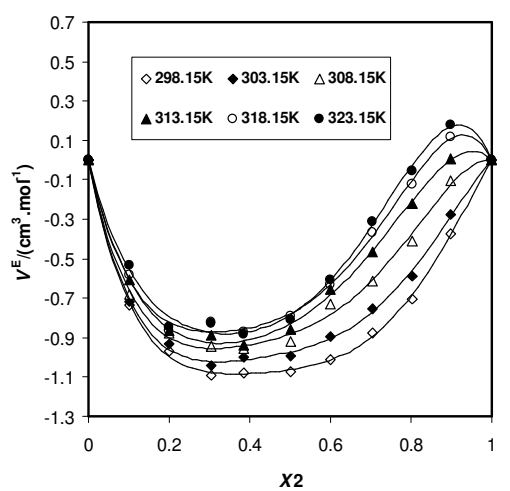

Fig. 4. Plots of excess molar volume vs mole fraction of isoPropanol + 0.01M SDS system at 298.15K, 303.15K, 308.15K, $313.15 \mathrm{~K}, 318.15 \mathrm{~K}, 323.15 \mathrm{~K}$ respectively.
The excess molar volumes of the mixtures which are under investigations may be considered to be the resultant of the above-mentioned competing interactions of the component molecules. All the components are polar compounds; the value of dipole moment $(\mu)$ being 1.85, 1.7, 1.69, 1.68 and $1.66 \mathrm{D}$ for Water, Methanol, Ethanol, n-Propanol, isoPropanol, respectively. Due to dipole-dipole interactions and hydrogen bonding between the components negative $V^{E}$ values are generally expected.

The molar volumes of Methanol, Ethanol, $n$-Propanol, and iso-Propanol, at $298.15 \mathrm{~K}$ are, respectively, 40.70, 56.95, 74.96 , and $77.21 \mathrm{~cm}^{3} \mathrm{~mole}^{-1}$. The Methanol and Ethanol molecules, being smaller there is possibility of partial accommodation of Methanol and Ethanol molecule in the interstices of the aqueous SDS molecules. Large and negative $V^{E}$ value of Methanol in SDS mixtures may be attributed to the occupation of void spaces of one component by other. The negative $V^{\mathrm{E}}$ of the systems under investigation indicates that the factors leading to contraction on mixing of the components dominate over the factors responsible for volume expansion. In view of the present state of our knowledge about the structure and the related properties of aqueous SDS, aliphatic alcohol, one can easily visualize that factors such as chemical contraction through hydrogen bonding between aqueous SDS and alcohol, the physical forces such as dipole-dipole interaction and the size difference between aqueous solution and alcohol, the 
hydrophobic hydration are all the important causes for volume contraction. For these particular systems the factors causing volume expansion are of little or no significance. The contractive forces thus predominate far more than the expansive forces, if any. The overall effect is thus contraction of volume.

The gradual contraction in volume on addition of aliphatic alcohol may be explained mainly by taking into account of formation of strong alcohol-aqueous SDS interactions due to $\mathrm{H}$-bonds and by the hydrophobic hydration with overall economy of space. When hydrogen bonded tetrahedral structure of liquid water is formed near a hydrophobic part of the solute the inert part (alkyl group of alcohol) of the solute fills the interstitial cavities of the structures. This loss of free space during hydrophobic hydration is larger than the increase in volume accompanying the increase of icelikeness. As the hydrocarbon part of alcohol increased, fewer sites are available to accommodate it, and the fraction of solute enclosed in interstitial spaces of cluster decreases and hence $V^{\mathrm{E}}$ becomes less negative as has been observed in the present systems: more negative $V^{\mathrm{E}}$ has been observed with Methanol and Ethanol systems than with $n$-Propanol systems. In the case of iso-Propanol systems, the $V^{\mathrm{E}}$ becomes much more negative than Methanol, Ethanol and $n$-Propanol systems. The strength of the intermolecular hydrogen bonding through in aqueous SDS and Alkanols, is not the only factor influencing the negative $V^{\mathrm{E}}$ of liquid mixtures, but the orientation of groups, molecular sizes and shapes of the components are also equally important. Larger the branch of alkanols, the aqueous structure around the hydrocarbon moieties of aliphatic alcohol is highly promoted leading to the formation of cages surrounding the alcohol molecules as a result more negative $V^{\mathrm{E}}$ is observed. Such results can also be seen in the work of Aminabhavi et al. [31] for branch-alcohol mixtures.

$n$-Propanol and iso-Propanol mixtures have slightly positive $V^{E}$ values at higher mole fractions. Unfavorable packing may, however, result due to disruption of the closely associated aqueous molecules on addition of alkanols and formation of new association between the unlike aqueous and an alkanol molecules. Reorganization of the pure components in the mixtures due to formation of different type of weaker bond and geometrical mismatch or steric hindrence may also result unfavorable packing and lead to expansion in volume [29-30].

Examination of the results shows that the temperature effects on $V^{E}$ are not much significant. However, for the systems (i.e $n$-Propanol and iso-Propanol) $V^{E}$ values are being positive at higher mole fractions, $V^{E}$ increases with temperature and for those with negative values, $V^{E}$ decreases with temperature.

\section{Conclusion}

The studies on the solution properties of ternary mixtures of Methanol $+0.005 \mathrm{M}$ SDS and $0.01 \mathrm{M}$ aqueous SDS, Ethanol $+0.005 \mathrm{M}$ SDS and $0.01 \mathrm{M}$ aqueous SDS, $n$-Propanol + $0.005 \mathrm{M}$ SDS and $0.01 \mathrm{M}$ aqueous SDS and iso-Propanol + $0.005 \mathrm{M}$ SDS and $0.01 \mathrm{M}$ aqueous SDS solutions, show strong solute-solvent interactions in aqueous SDS region, the aqueous SDS molecules form highly ordered structures through hydrogen bonding around the hydrocarbon moieties of alcohols. The values of excess molar volumes for all the systems are negative and showing minima at water SDS rich region. The observed values of $V^{E}$ for the mixtures have been explained in terms of specific intermolecular interactions and structural contributions. Although the value of density and excess molar volume of the studied systems in post-micellar aqueous SDS solutions (0.01M SDS) are higher than in pre-micellar (0.005M SDS ) solution systems, but the minima position of the excess molar volumes are not varied by the change of surfactant concentration.

\section{Acknowledgements}

We are grateful for financial support by the CASR of Khulna University of Engineering \& Technology (KUET), Bangladesh in the form of Research Project.

1. Tanford C., 1973. The Hydrophobic Effect - Formation of Micelles and Biological Membranes, Wiley- Interscience, New York.

2. Kabir M.H., M.A. Motin and M.E. Huque, 2004. Phys. Chem. Liq., 42(3), 279.

3. Dey P.C., M.A. Motin, T.K. Biswas and E.M. Huque, Monat. Chem., 134, 797

4. Afroz S., M.A. Motin, T.K. Biswas and E.M. Huque, 2003. Phys. Chem. Liq., 41, 249.

5. Al-Azzawi S.F., and A.M. Awwad, 1990. J. Chem. Eng. Data, 35, 411.

6. Al-Azzawi S.F., and A.M. Awwad, 1990. Fluid Phase Equilib., 60, 289.

7. Awwad A., M. A.H. Al-Dujaili and H.E. Salman, 2001. Iraqi J. Chem., 27, 115.

8. Awwad A., M. A.H. Al-Dujaili and N.R. Alian, 2000. Iraqi J. Chem., 26, 94.

9. Sacco A., A.K. Rakshit, 1975. J. Chem. Thermodyn., 7, 257.

10. Karvo M. J., 1980. Chem. Thermodyn., 12, 635.

11. Karvo M. J., 1982. Chem. Thermodyn., 15, 821. 
12. Jannelli L., M. Pansini and R. Jalenti, 1984. J. Chem. Eng. Data, 29, 263.

13. Liu H. and M. Hai, 2010. J. Chem. Eng. Data, 55, pp. 354357.

14. Lide D.R., 1992. CRC Handbook of Chemistry and Physics. 73rd edn. CRC Press, Boca Raton, FL.

15. Roy M.N., A. Sinha and B. Sinha, 2005. J. of Soln. Chem., Vol. 34( 11), pp. 1311-1325.

16. Zarei H. A., N. Mirhidari and Z. Zangeneh, 2009. J. Chem. Eng. Data, 54, pp. 847-854.

17. Timmermans J., 1950. Physico-chemical constants of pure organic compounds, pp. 304-457. Elsevier Publishing co., New York.

18. Kabir M.H., M.A. Motin and M.E. Haque, 2004. Physics and Chemistry of liquids, 42. pp. 279-290.

19. Sovilj M. and B. Barjaktarovic, 2000. Bulletin of the Chemists and Technologists of Macedonia, 19, pp. 73-78.

20. Radovic I. R., M. L. Kijevcanin, A. Z. Tasic, B. D. Djordjevic and S. P. Erbanovic, 2009. J. Serb. Chem. Soc. 74, pp. 13031318.

21. Acevedom I., 1988. J. Chem.Therm. 66, 367.
22. Nikam P. S., L. N. Shirsat, and M. Hasan, 1998. J. Chem. Eng. Data, 43, 732-737.

23. Marigliano G. and H. N. Solimo, 2002. J. Chem. Eng. Data, 47, 796-800.

24. Gurtu J. N. and R. Kapoor, 1987. Adv. Exp. Chem. 1, 338346.

25. Motin M.A., M.H. Kabir and M. E. Haque, 2005. Physics and Chemistry of liquids, 43, pp. 123-137.

26. Nikam, P. S., M. C. Jadhav and M. Hasan, 1996. J. Chem. Eng. Data, 41 (5), pp 1028-1031.

27. Wei Chien I. and R. L. Rowley, 1984. J. Chem. Eng. Data, 29, 336.

28. Saleh M.A., S. Akhtar, M. S. Ahmed and M. H. Uddin, 2002. Phys . Chem. Liq., 40, 621-635".

29. Andrzej J., Treszczanowicz and G.C. Benson, 1977. J. Chem. Thermodyn., 9, 1189.

30. Goates J.R., J.B. Ott and R.B. Grigg, 1981. J. Chem. Thermodyn., 13, 907.

31. Aminabhavi T. M. and B. Gopalakrishna, 1996. J. Chem. Eng. Data. 40, 452. 
Dhaka Univ. J. Sci. 60(1): 129-136, 2012 (January)

*Corresponding author: abdulmotin75@yahoo.com (M. A. Motin), Fax : +88 041774403 
